\title{
Investigation of Relations between Atomic Number and Composition Weight Ratio in PZT and SMA and Prediction of Mechanical Behavior
}

\author{
V. Monfared* \\ Department of Mechanical Engineering, Zanjan Branch, Islamic Azad University, Zanjan, Iran, P.O. BOX 49195-467 \\ AND M.R. KHALILI \\ Department of Mechanical Engineering, K. N. Toosi University of Technology, Tehran, Iran
}

(Received December 15, 2010; in final form March 19, 2011)

\begin{abstract}
In this paper there is presented the mechanical behavior of the one lead-zirconate-titanate by its atomic number and its certain mechanical behavior is simulated by the mathematical modeling and ABAQUS software for smart materials, as well as prediction of mechanical behaviors. Also in this smart material $(\mathrm{Pb}-\mathrm{Zr}-\mathrm{Ti})$ the grain size according to molar ratio is studied. This mechanical behavior is modeled by the exponential and polynomial formula from one to ten degree. Next there are defined the new relations for mechanical behavior and composition weight ratio, between composed elements for triplex lead-zirconate-titanate and dual smart materials. Triplex lead-zirconate-titanate has been selected as main and important material for the development of smart structures. In addition, the relation between atomic number and weight ratio in one smart material (Ni-Ti) is investigated briefly. In this work, change of resistance and voltage, pressure, grain size, molar ratio, residual stress, content of zirconate and the other mechanical properties are studied.
\end{abstract}

PACS: 31.15.-p, 31.10.+z, 32.10.-f

\section{Introduction}

Lead-zirconate-titanate (PZT) ceramics, having various $\mathrm{Pb}-\mathrm{Zr}-\mathrm{Ti}$ molar ratios ranging from 0.85 to 1.04 , have been sintered at $900-1200^{\circ} \mathrm{C}$ for $2 \mathrm{~h}$ to investigate the change in photovoltaic properties, as well as grain size. The residual stress of multilayer's in piezoelectric microelectromechanical system structures influence their electromechanical properties and performance [1]. This paper explains the development of residual stress in $8 \mu \mathrm{m} \mathrm{Pb}\left(\mathrm{Zr}_{0.25} \mathrm{Ti}_{0.75}\right) \mathrm{O}_{3}$ for microsize. Uniform illumination of homogeneous noncentro-symmetric crystals, as well as polarized ferroelectric polycrystallines, generates a steady-state electric current. Under an open-circuit (OC) condition, photovoltaic current can produce a high voltage that noticeably oversteps band gap energies without external fields. In this paper, we investigate and present the experimental results on the photovoltaic effect in PZT ceramics by parameters changes. Then mathematical modeling is presented, diagrams and curves show the mechanical behaviors, new formulation with respect to atomic number, and relative simulations, and next the composition's ratio of some smart structures to compose and mix to make of one smart materials (SMA) is defined [2-4].

\footnotetext{
* corresponding author; e-mail: Vahid_monfared_57@yahoo.com
}

\section{Mathematical modeling for experiment results}

Models and patterns of PZT ceramics were prepared by the conventional solid-state reaction process. In Fig. 1, $\mathrm{Pb}\left(\mathrm{Zr}_{0.25} \mathrm{Ti}_{0.75}\right) \mathrm{O}_{3}$ was chosen as the basic composition, for which molar ratios of PZT in the samples were modified to range from 0.85 to 1.04 by adjusting the weights of the raw materials. Crystalline phases formed were identified by a powder X-ray diffraction technique (XRD). Scanning electron microscopy (SEM) was used to examine the microstructures of the samples that were ground, burnished and then chemically etched with $10 \% \mathrm{HBr}$ solution containing several drops of $50 \% \mathrm{H}_{3} \mathrm{PO}_{4}$ in $100 \mathrm{ml}$ of $10 \% \mathrm{HBr}$. Average grain size was computed by calculating the equivalent circular sizes of about 150 grains on the SEM micrographs of each pattern. Figures 1, 2 show the grain size with respect to molar ratios, photovoltaic properties of PZT ceramics having different $\mathrm{Pb}-\mathrm{Zr}-\mathrm{Ti}$ molar ratio. The photovoltaic current enhanced quickly when the molar ratio was smaller than 1.00 . The photovoltaic effect diminished once between the molar ratios of 0.94 and 1.00, but enhanced subsequently to show a dispersed distribution when the molar ratio was smaller than 1.00 .

This result shows that the enhanced photovoltaic effect in PZT ceramics with nonstoichiometric composition is not obvious and is not only due to grain size. The fol- 


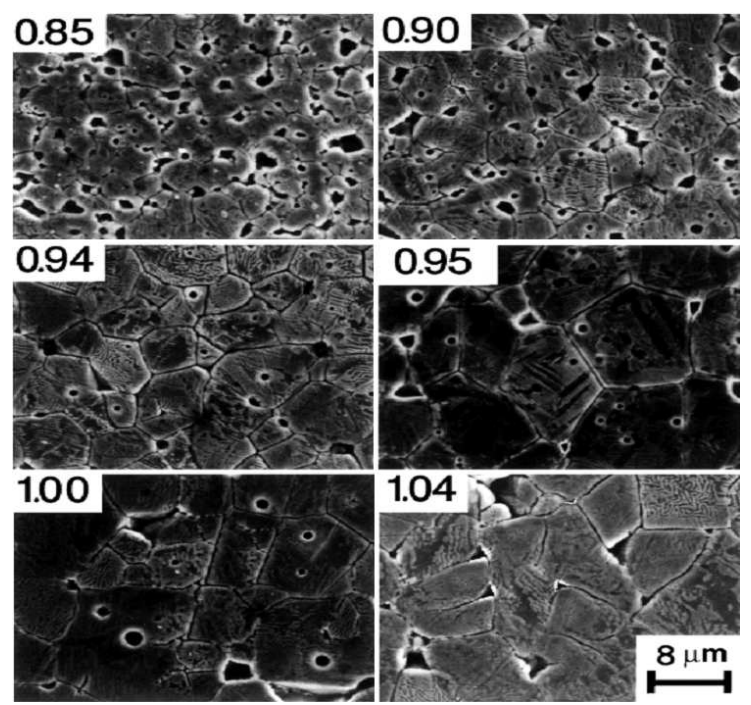

Fig. 1. Burnished and etched surfaces of PZT ceramics sintered at $1200{ }^{\circ} \mathrm{C}$ for $2 \mathrm{~h}$ observed by SEM as a function of molar ratio.

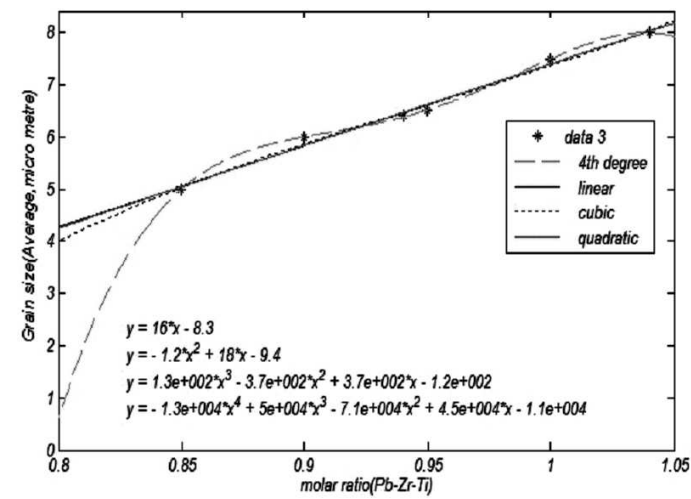

Fig. 2. $\mathrm{PZT}$ molar ratio $(\mathrm{Pb}-\mathrm{Zr}-\mathrm{Ti})$.

lowing Fig. 2 shows that the relation between molar ratio and grain size.

Figure 2 shows the variation of the average grain size with the molar ratio of PZT ceramics. The average grain size exhibited a trend to abate with diminishing molar ratio from 1.04 to 0.85 , but a less consistent result was obtained between molar ratios of 0.94 to 1.00. In this range, the grain size becomes once large, reaching a maximum at the molar ratio of 0.95 . Also, we have a large shift in grain size between 0.96 and 1.00 that is due to growth of grain. Now, in this work, the mathematical model for mechanical behavior of PZT is presented, that is

$$
\begin{aligned}
& \mathrm{AGS}=\left[-13(\mathrm{MR})^{4}+50(\mathrm{MR})^{3}-71(\mathrm{MR})^{2}\right. \\
& \quad+45(\mathrm{MR})-11] \times 10^{3},
\end{aligned}
$$

where AGS is average grain size in $\mu \mathrm{m}$ and MR is molar ratio. This relation is closed to the mechanical behavior of mentioned PZT. Now there is presented the mathe- matical model for relations between change in resistance with a change in pressure and time. These samples after fabrication and production were subjected to analytical and electrical characterization. The fabricated samples are characterized with respect to pressure. They are subjected to different pressures and the electrical resistance is measured in each case. The initial resistance of fabricated material is around $5 \mathrm{M} \Omega[5,6]$.

These presented diagrams and results in PZT's are collected from results and experiments of this project and the other paper researches that these results are the same as in many PZTs.

Now the mathematical models are presented for mechanical behavior of PZT, first for relation between resistance and pressure in state of dynamic pressure, Figs. 3a, b, that is

$$
P_{\mathrm{d}}=39 R_{\mathrm{d}}^{5}-100 R_{\mathrm{d}}^{4}+92 R_{\mathrm{d}}^{3}-32 R_{\mathrm{d}}^{2}+1.5 R_{\mathrm{d}}+5,
$$

and by exponential

$$
P_{\mathrm{d}}=\exp \left(-0.195 R_{\mathrm{d}}+1.568\right),
$$

where $R_{\mathrm{d}}, R_{\mathrm{S}}$ are dynamic and static resistances $(\mathrm{M} \Omega)$ and pressure $P_{\mathrm{d}}$ is in MPa units. Then the mathematical models are presented for mechanical behavior of PZT, for relation between resistance and pressure in state of static pressure, Figs. 3c, d, that is

$$
P_{\mathrm{s}}=-35 R_{\mathrm{s}}^{5}+97 R_{\mathrm{s}}^{4}-99 R_{\mathrm{s}}^{3}+46 R_{\mathrm{s}}^{2}-10 R_{\mathrm{s}}+5,
$$

and by exponential

$$
P_{\mathrm{s}}=\exp \left(-0.164 R_{\mathrm{s}}+1.53\right),
$$

where these formulations are obtained by programming and coding in Matlab software. $P_{\mathrm{s}}$ is static pressure. Next the mathematical modeling and simulations are presented for explanation and analyzing mechanical behavior of PZT for investigation of variation in initial resistance after storage at $130{ }^{\circ} \mathrm{C}$ for $800 \mathrm{~h}$ for pressure sensitive devices based on phase transformation, Fig. 4a.

The mathematical modeling in form of polynomial is

$$
R[\mathrm{M} \Omega]=-0.00013 T+5,
$$

and the exponential form is

$$
R=\exp (-0.000047 T+1.61),
$$

where $R$ is resistance $(\mathrm{M} \Omega)$ and $T$ is time $(\mathrm{h})$ shown in Fig. 4b. Variation in residual stress (MPa) in mentioned PZT with respect to time $(\mathrm{h})$ showed stress relaxation as seen in Fig. 5.

Stress relaxation in PZT can be explained by either structural changes or adsorption of moisture into the compound of PZT through the grain boundaries [7].

For structural relaxation, as the stress itself is the driving force, a change in the sign of the stress will not occur. Next the mathematical modeling for mechanical behavior is presented [8].

According to Fig. 5, the mathematical modeling for the relation between residual stress $(\mathrm{MPa})$ and time $(\mathrm{s})$ is 


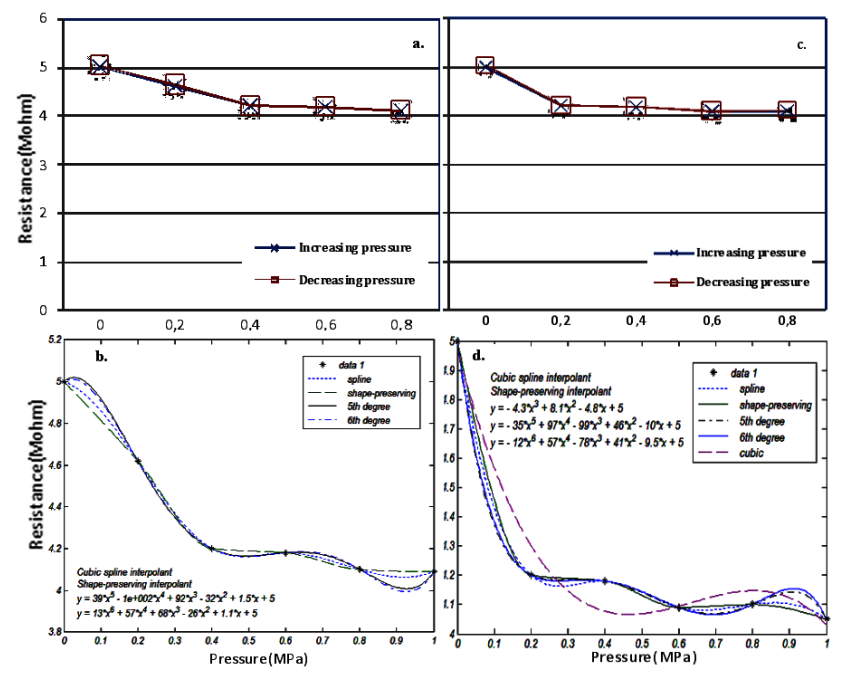

Fig. 3. (a) Variation in resistance with change in dynamic pressure. (b) Mathematical modeling and variation in resistance with change in dynamic pressure. (c) Variation in resistance with change in static pressure. (d) Mathematical modeling and variation in resistance with change in static pressure.

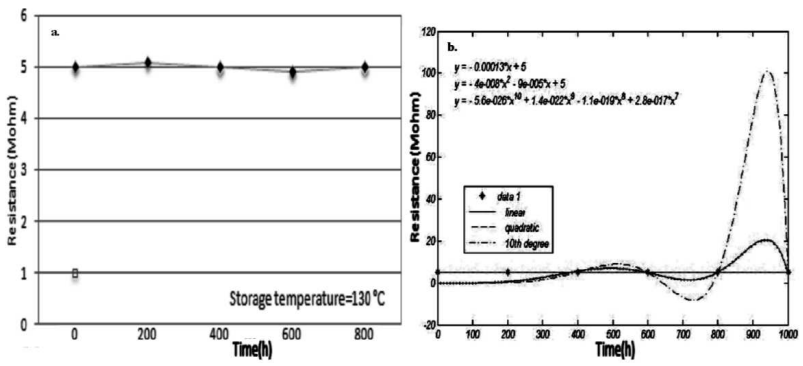

Fig. 4. (a) Variation in initial resistance after storage at $130{ }^{\circ} \mathrm{C}$ for $800 \mathrm{~h}$ for pressure sensitive devices based on phase transformation. (b) Mathematical modeling and simulation of mechanical behavior resistance by time after storage at $130^{\circ} \mathrm{C}$ for $800 \mathrm{~h}$ for pressure sensitive devices based on phase transformation.

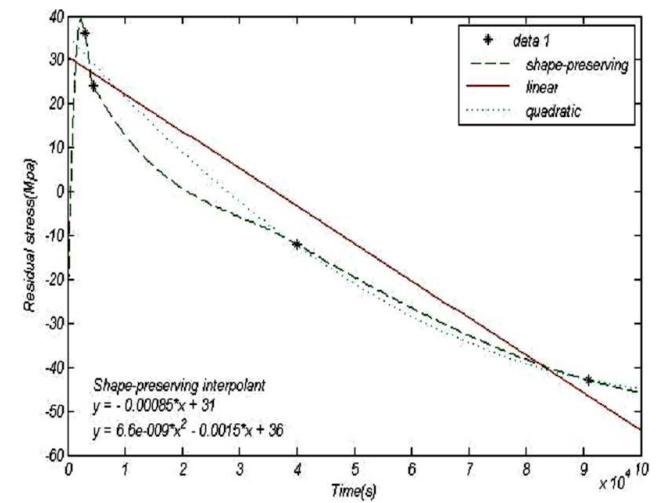

Fig. 5. Residual stress of PZT as a function of time by stress changes with time from tensile to compressive.

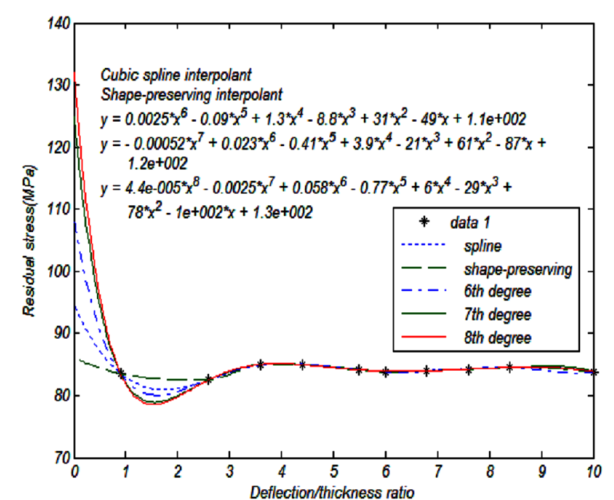

Fig. 6. Mechanical behavior and simulation of residual stress as a function of deflection/thickness ratio by using the full range of load deflection data.

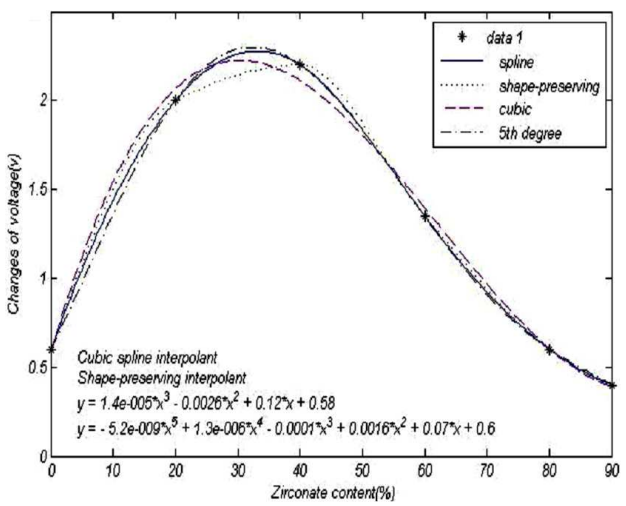

Fig. 7. Change of voltage for different $\mathrm{Zr}$ content.

$$
R=0.0000000066 T^{2}-0.0015 T+36
$$
and

$$
R=-0.00085 T+31 .
$$

The mechanical behavior simulation for a one PZT device (smart material) with diameter and thickness about $1 \mathrm{~mm}$ and mathematical modeling according to Fig. 6, is

$$
\begin{aligned}
\hat{R} & =0.0025 Z^{6}-0.09 Z^{5}+1.3 Z^{4}-8.8 Z^{3}+31 Z^{2} \\
& -49 Z+110,
\end{aligned}
$$

where $\hat{R}$ is residual stress in MPa and $Z=\frac{\text { deflection }}{\text { thickness }}$.

The gas sensitivities for the PZT films with different $\mathrm{Zr} / \mathrm{Ti}$ ratios were also characterized by the $I-V$ measurement. Figure 7 shows the turn on voltage shift versus the $\mathrm{Zr}$ content in the PZT films measured at 1000 ppm hydrogen gas diluted in air. Figure 7 shows the mechanical behavior and simulation of a one PZT (smart material), also this figure presents relation between $\mathrm{Zr}$ content and change of voltage.

The mathematical modeling and formulation is

$$
\begin{aligned}
& \mathrm{CoV}=0.0000000052(\mathrm{Zr})^{5}+0.0000013(\mathrm{Zr})^{4} \\
& \quad-0.0001(\mathrm{Zr})^{3}+0.0016(\mathrm{Zr})^{2}+0.07(\mathrm{Zr})+0.6
\end{aligned}
$$

where $\mathrm{CoV}$ is change of voltage and $\mathrm{Zr}$ is zirconate content. 


\section{Relation between atomic number and mechanical behavior of PZT}

Now, relation between atomic number and resistance and dynamic pressure, Figs. 3a, b, is presented

$$
\begin{aligned}
& R_{\mathrm{d}}=\exp \left(\left(\frac{-Z^{3}+T^{2}+T P}{T Z^{2}+P Z^{2}}\right) P_{\mathrm{d}}\right. \\
& \left.+\frac{P T-Z P-T Z}{P}\right),
\end{aligned}
$$

where $Z$ is atomic number of zirconate, $T$ is atomic number of titanate and $P$ is atomic number of lead. Atomic numbers of zirconate, titanate and lead are 40, 81 and 80, respectively. That is, the mechanical properties of PZT (resistance $\left(R_{\mathrm{d}}\right)$ and dynamic pressure $\left(P_{\mathrm{d}}\right)$ ) have significant and logical relation with atomic numbers $(Z=40$, $T=22, P=82$ in above formulation). Therefore, we can predict the mechanical behavior in each point by relations (2.1)-(3.1). For example, according to Eq. (2.11), we can determine change of voltage $(\mathrm{CoV})$ in point of $10.13 \%$ (zirconate content) without any experiment. The other relation and formulation for the one PZT for the triplex (three elements) PZT, can be of the following form:

$$
{ }^{2 t+2} \mathrm{~A}{ }^{t} \mathrm{~B}{ }^{\frac{t}{2}+2} \mathrm{C}=\text { one smart material }(\mathrm{PZT}),
$$

where $\mathrm{A}, \mathrm{B}$ and $\mathrm{C}$ are the three elements (triplex elements) and $t$ is the atomic number of element $\mathrm{B}$, also $2 t+2$ and $\frac{t}{2}+2$ are the atomic number of $\mathrm{A}$ and $\mathrm{C}$ elements. For example for $t=40$ it is

$$
{ }^{82} \mathrm{~A}{ }^{40} \mathrm{~B}{ }^{22} \mathrm{C}={ }^{82} \mathrm{~Pb}{ }^{40} \mathrm{Zr}{ }^{22} \mathrm{Ti} \text {. }
$$

\section{Relation between atomic number and weight ratio in triplex PZT and dual (SMA, suitable recovered strain) in order to high performance}

According to the above formulation, that is, ${ }^{2 t+2} \mathrm{~A}^{t} \mathrm{~B}{ }^{\frac{t}{2}+2} \mathrm{C}$ the new relation between the atomic number and composition weight ratio of one PZT may be presented. According to the mentioned relations, $t$ is the atomic number of $\mathrm{B}$ element. Therefore the mathematical modeling for weight ratio of $\mathrm{PZT}$ is

$$
\begin{aligned}
& \text { content of element }(\mathrm{C})=\mathrm{CoE}_{3}(\mathrm{C}) \% \\
& =\frac{\text { sum of atomic numbers of elements B and } \mathrm{C}}{\text { atomic number of element A }} \\
& =\frac{\frac{3 t}{2}+2}{2 t+2}
\end{aligned}
$$

content of element $(\mathrm{B})=1-\mathrm{CoE}_{3}(\mathrm{C})=\mathrm{CoE}_{3}(\mathrm{~B})$,

where number 3 in $\mathrm{CoE}_{3}$ is symbol of triplex. For example, for $\mathrm{Pb}-\mathrm{Zr}-\mathrm{Ti}$ we have

$$
\begin{aligned}
& \mathrm{CoE}_{3}(\mathrm{~B}) \% \approx 0.25 \Rightarrow \approx 25 \% \mathrm{Zr} \Rightarrow \mathrm{CoE}_{3}(\mathrm{C}) \approx 0.75 \\
& \quad \Rightarrow \approx 75 \% \mathrm{Ti} .
\end{aligned}
$$

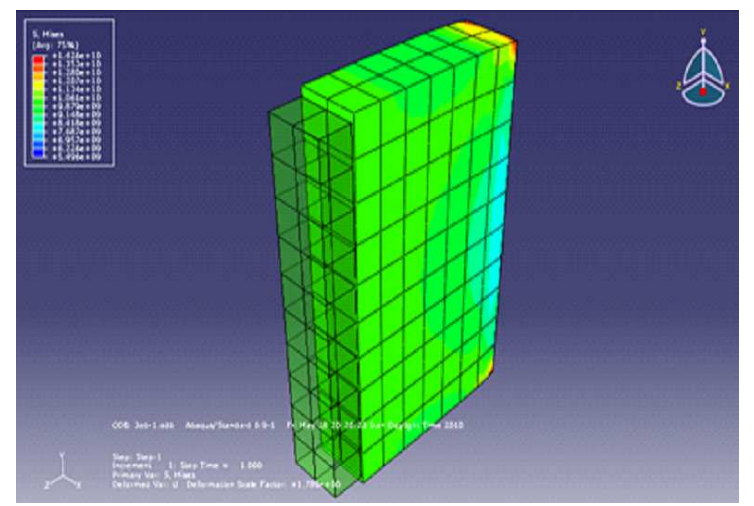

Fig. 8. ABAQUS simulation of composition of dual SMA, $\mathrm{Ni}_{78} \mathrm{Ti}_{22}$ in state of Mises stress analysis in addition to thermal loading.

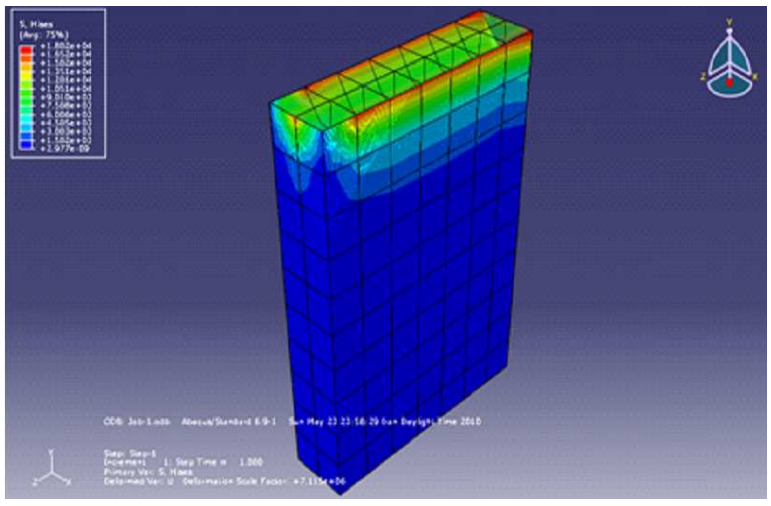

Fig. 9. ABAQUS simulation of composition of dual SMA, $\mathrm{Ni}_{78} \mathrm{Ti}_{22}$ in state of Mises stress analysis with thermal loading.

Therefore, according to the mentioned relation, $\mathrm{Pb}\left(\mathrm{Zr}_{0.25} \mathrm{Ti}_{0.75}\right) \mathrm{O}_{3}$ is the ideal and suitable composition in order to high performance for PZT.

In addition, one formulation for dual and twin SMA with high performance and suitable recovered strain is presented. This formulation is

$$
\begin{aligned}
& \text { content of basic element }(\%)=\mathrm{COBE}_{2}(\mathrm{X}) \\
& =\frac{\text { atomic number of added element }}{\text { atomic number of basic element }} \times 100 .
\end{aligned}
$$

For example, to dual elements, if we have two elements $\mathrm{X}, \mathrm{Y}$ with atomic number of $x, y$ and $\mathrm{X}$ is basic element, that is

$$
\begin{aligned}
& \text { atomic number } x \mathrm{X}^{\text {atomic number }}{ }^{y} Y, \\
& \text { content of basic element }(\%)=\frac{y}{x} \times 100 \%, \\
& \text { content of element }(\mathrm{Y})=\mathrm{COE}_{2}(\mathrm{Y}) \\
& \quad=\left(1-\mathrm{COBE}_{2}(\mathrm{X})\right) \times 100 \%,
\end{aligned}
$$

where number 2 in $\mathrm{COBE}_{2}(\mathrm{X})$ is symbol of dual and 


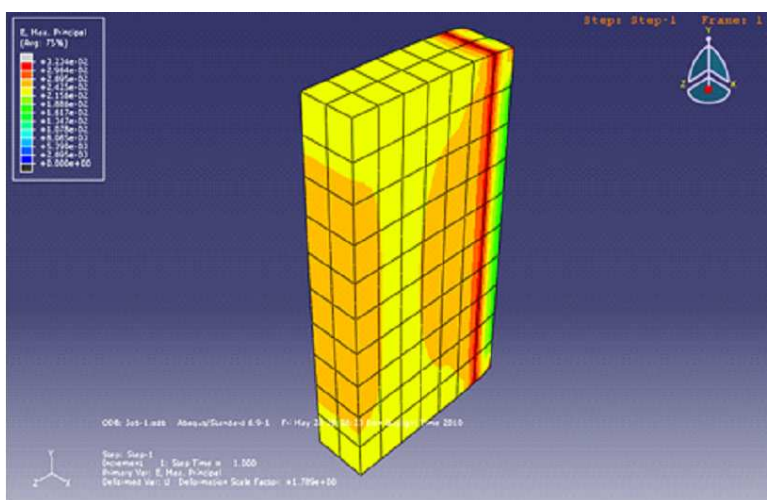

Fig. 10. ABAQUS simulation of composition of dual SMA, $\mathrm{Ni}_{78} \mathrm{Ti}_{22}$ in state of maximum principal analysis with thermal loading.

twin. Also, the following simulations with ABAQUS software justified the above formulations for smart materials (SMA), Figs. 8-10 and recovered strain is almost 7\%.

\section{Conclusions}

- Relation between atomic number and resistance and dynamic pressure (mechanical behaviors) in PZT (triplex elements), is presented. Relation between atomic number and weight ratio in triplex PZT and dual SMA (suitable recovered strain) in order to high performance is studied and presented.

- Mathematical models and simulation (MATHEMATICAL \& ABAQUS) for mechanical properties and prediction of mechanical properties for PZT is investigated and presented. Relation between molar ratio and grain size is investigated.

- The photovoltaic effect in PZT (smart material) has been verified with various molar ratios of $\mathrm{Pb}-\mathrm{Zr}$-Ti ranging from 0.85 to 1.04 . The results show that several factors, such as zirconate content, molar ratio, secondary phase, and grain size should be considered to obvious understanding of the photovoltaic change. It has been verified and studied that the sensitivities of the turn on voltage changes in dc $I-V$ curves is closely dependent on different zirconate content and hydrogen concentrations.

- Characterizations of resistance change by dynamic and static pressure-sensitive in smart-materials based on phase transition have been presented and discussed.

- Feeble and weak hysteresis free response is observed. Devices under static and dynamic pressures were prepared and the results were justified the same.

\section{Acknowledgments}

The author is extremely thankful to Dr. M.R. Khalili, Dr. Zahra Najmi (gynecologist: my spouse), Mr. A.H. Monfared (MSc in Artificial Intelligence: my brother), for their help in fabrication and the other aspects.

\section{References}

[1] S. Trolier-McKinstry, P. Muralt, J. Electroceram. 12, 7 (2004).

[2] M. Addington, D. Schodek, Smart Materials and New Technologies, Architectural Pub., Harvard University 2005.

[3] J. Deng, W. Zhu, O.K. Tan, X. Yao, Sensors Actuators $B$ 77, 416 (2001).

[4] V.M. Fridkin, Photoferroelectrics, Springer-Verlag Pub., 1979.

[5] B. Jaffe, W.R. Cook Jr, H. Jaffe, Piezoelectric Ceramics, Academic Pub., 1971.

[6] P.K. Khanna, N. Kumar, Amanpal Singh, Chandra Shekhar, Y.K. Jain, H.C. Pandey, Mater. Lett. 63, 1958 (2009).

[7] E. Hong, R. Smith, S.V. Krishnaswamy, C.B. Freidhoff, S. Trolier-McKinstry, Thin Solid Films 510, 213 (2006).

[8] L. Lian, N.R. Sottos, J. Appl. Phys. 95, 629 (2004). 